\title{
The Effectiveness of Educational Support to Orphans and Vulnerable Children in Tanzania and Uganda
}

\author{
Mary H. Shann, ${ }^{1}$ Malcolm H. Bryant, ${ }^{2,3}$ Mohamad I. Brooks, ${ }^{3}$ Paul Bukuluki, \\ Denis Muhangi, ${ }^{4}$ Joe Lugalla, $^{5,6}$ and Gideon Kwesigabo ${ }^{6,7}$ \\ ${ }^{1}$ School of Education, Boston University, Boston, MA 02215, USA \\ ${ }^{2}$ Center for Global Health and Development, Boston University, Boston, MA 02118, USA \\ ${ }^{3}$ Department of International Health, School of Public Health, Boston University, Boston, MA 02118, USA \\ ${ }^{4}$ Department of Social Work and Social Administration, Makerere University, P.O. Box 7062, Kampala, Uganda \\ ${ }^{5}$ Department of Anthropology, University of New Hampshire, Durham, NH 03824, USA \\ ${ }^{6}$ Centre for Strategic Research and Development, P.O. Box 33335, Dar es Salaam, Tanzania \\ ${ }^{7}$ School of Public Health and Social Sciences, Muhimbili University of Health and Allied Sciences, P.O. Box 65015, \\ Dar es Salaam, Tanzania
}

Correspondence should be addressed to Mary H. Shann; shann@bu.edu

Received 26 October 2012; Accepted 23 November 2012

Academic Editors: C. C. Branas and K. Hacker

Copyright (C) 2013 Mary H. Shann et al. This is an open access article distributed under the Creative Commons Attribution License, which permits unrestricted use, distribution, and reproduction in any medium, provided the original work is properly cited.

\begin{abstract}
Little evidence is available to assist policy makers and donors in deciding what kinds of programs in developing countries are more likely to be effective in supporting the entry and continuation of OVC in secondary schools. This is particularly important for females whose education has direct bearing on child mortality in the next generation. This study gathered four kinds of educational outcome measures in two East African countries ravaged by the AIDS/HIV pandemic. The goal was to determine whether direct scholarship aid to individual students versus various forms of block grants would be more effective in promoting lower rates of absenteeism, lower dropout rates, higher national examination scores, and higher pass rates for OVC of both genders. Insufficient evidence was available for recipients of scholarships, but OVC with block grant support performed as well or better than their non-OVC counterparts, and significantly better than OVC without support. Contrary to popular belief, girls had lower rates of absenteeism. There were no gender differences in dropout. However, boys consistently outperformed girls on academic tests. Insufficient data systems continue to impede more detailed analysis.
\end{abstract}

\section{Purpose}

This research investigated the relative effectiveness of various educational delivery service models to orphans and vulnerable children (OVC) in two East African countries ravaged by the AIDS pandemic. It also examined gender differences in students' educational outcomes.

\section{Perspectives}

In addition to the intrinsic importance of education and its role in economic growth, a causal link has long been established between education and a range of health outcomes $[1,2]$. A meta-analysis of 175 studies showed that for every year of increase in the education of women of reproductive age, child mortality decreased by $9.5 \%$ [3]. Increasing access to education and retention at school is instrumental not only in the health and wellbeing of the individual, but also in their future children and families.

Being orphaned or made vulnerable can play a role in whether a child goes to school. OVC may lose access to school for several reasons including poverty, need for domestic labor, need for income-generating activities, stigmatization, and parental sickness or death. School enrollment inequities among all types of orphans have been documented throughout sub-Saharan Africa ([4-8]; Bicego et al. [9]). One estimate suggests that orphans are approximately 13\% less likely to attend school than nonorphans [4]. Studies have also shown that disparities in grade progression were found in 
several countries including Botswana, Niger, Ghana, Kenya, Tanzania, and Zimbabwe ([7]; Bicego et al. [9]). Appropriate grade progression is important because losing ground in school places children at higher risk for failing and dropping out.

Africa has one of the lowest education completion rates in the world [10]. The low transition rate into secondary schools is partially a result of caregivers not being able to pay for a child's education. Secondary schools are rarely free. Even in countries where universal secondary education is guaranteed by the government (such as Uganda), students must pay additional fees imposed by the schools. In other countries, students must pay for tuition and other schoolrelated expenditure such as books, uniforms, and multiple fees for buildings, maintenance, desks, and so forth.

Various mechanisms of funding have been applied by the United States Agency for International Development (USAID) and other development partners to support the education of OVC, including scholarships and block grants. Scholarships are individual payments made to, or on behalf of, a child to pay for part or all of their education. Block grants are fixed-sum grants to local or regional educational systems or institutions that give the recipient organization broad flexibility to design and implement designated programs. While both mechanisms have been used in various developing countries, their relative impact on both the quantity and quality of education for OVC has not been evaluated.

\section{Methods and Data Sources}

The study employed a four-year, retrospective record review using a mixed method approach and multiple data sources enabling the triangulation of results and interpretations.

The quantitative components of the study took three forms: QUANT I analyzed individual level data from students classified as ever-supported OVC, never-supported OVC, or non-OVC, QUANT II looked at aggregate data from intervention and control schools, and QUANT III examined cost data.

The qualitative components drew on interviews, focus groups, observational techniques, and document analysis to learn about the intervention used by each NGO and its context from the point of view of the primary recipients and other knowledgeable stakeholders.

QUANT I is the focus of this paper. It addressed how well individual OVC fared under the block grant and scholarship programs as compared to their OVC peers and non-OVC peers who did not receive any targeted benefit. Outcome measures included absenteeism, dropout, pass rates, and national examination scores. Basic descriptive statistics were calculated for main variables of interest to describe key characteristic of the study sample. Comparisons of means were conducted through paired $t$-test and one-way analysis of variance. A bivariate analysis was conducted using simple logistic regression to assess the associations between the primary outcome and predictor variables. Statistically significant associations at $P<0.05$ are highlighted as appropriate in the different analyses.
It was important to study both Tanzania and Uganda to enable comparisons in multiple settings across two countries at the heart of the AIDS pandemic with similar educational systems inherited from their colonial past. Five NGOs illustrated different models of delivering educational support.

\section{Study Procedures}

Prior to implementation, ethical approvals were obtained from the US authors' IRB, the Ugandan National Research Council, and the Tanzanian National Institute for Medical Research. In addition, formal approvals were obtained from the Ugandan Ministry of Education and Sports, and the Tanzanian Ministry of Education and Vocational Training.

Consent forms and study instruments were prepared in English. In Tanzania the study was administered in Swahili, and all instruments and consents were translated and backtranslated to ensure consistency. In addition, official certifications of consent form translations were provided to the BU IRB. In Uganda, study instruments and consent forms were administered in English.

Data collectors underwent three days of training in quantitative and qualitative methods prior to the study. Training was conducted jointly by the local university research partners and US authors and involved didactic training and role playing. During this training, we also conducted field testing of the instruments and made any necessary revisions. Data collectors visited schools in teams of two, taking approximately three days to collect all required data from each school. Fifty OVC receiving support from one of the target NGOs were identified at each school and matched with the same number of OVC not receiving support and non-OVC children in the same class or year of schooling. Attendance and performance records were then obtained for each child for the current year and the four preceding years. Data were regularly assessed for reliability throughout the data collection period by the local investigators and US data manager.

Qualitative data were collected through key informant interviews of school headmasters, government education officers, NGO country and regional representatives, and community leaders. Focus group discussions were conducted for supported OVC children and community members.

Following data analysis, findings were presented in a series of dissemination meetings in each country to discuss relevance of study findings with key stakeholders.

\section{Results}

A total of 5,738 children were recruited to the study: 1,930 in Tanzania and 3,808 in Uganda. Their characteristics are summarized in Table 1. The two-to-one ratio of Ugandan to Tanzanian subjects reflected that ratio of service delivery by NGOs in each country. The design called for approximately 250 students receiving support from each $\mathrm{NGO}$ in each country. Students at every grade level in Tanzania were older than their counterparts in Uganda which reflects the difference in school enrolment age in the two countries. In Uganda, children begin primary school at 6 years of age, 
TABLE 1: Study sample characteristics.

\begin{tabular}{lcc}
\hline & $\begin{array}{c}\text { Tanzania } \\
(n=1930)\end{array}$ & $\begin{array}{c}\text { Uganda } \\
(n=3808)\end{array}$ \\
\hline Mean student age (years) & & \\
F1/S1 student (Std Dev) & $15.8(1.4)$ & $14.5(2.0)$ \\
F2/S2 student (Std Dev) & $16.8(1.4)$ & $15.6(1.9)$ \\
F3/S3 student (Std Dev) & $17.6(1.4)$ & $16.6(1.9)$ \\
F4/S4 student (Std Dev) & $18.3(1.2)$ & $17.5(1.9)$ \\
Gender & & \\
Male (\%) & $1013(52.5 \%)$ & $2003(52.6 \%)$ \\
Female (\%) & $917(47.5 \%)$ & $1805(47.4 \%)$ \\
Student status & & \\
OVC Ever-supported (\%) & $498(25.8 \%)$ & $777(20.4 \%)$ \\
OVC Never-supported (\%) & $721(37.4 \%)$ & $1531(40.2 \%)$ \\
Non-OVC (\%) & $711(36.8 \%)$ & $1500(39.4 \%)$ \\
Student NGO support & & \\
Africare (\%) & $243(12.6 \%)$ & $256(6.7 \%)$ \\
ICOBI (\%) & - & $257(6.7 \%)$ \\
AVSI (\%) & - & $264(6.9 \%)$ \\
CRS (\%) & $255(13.2 \%)$ & - \\
None (\%) & $1432(74.2 \%)$ & $3031(79.6 \%)$ \\
Availability of student records & & \\
Year 1: 2006-2007 (\%) & $232(12.0 \%)$ & $662(17.4 \%)$ \\
Year 2: 2007-2008 (\%) & $747(38.7 \%)$ & $1130(29.7 \%)$ \\
Year 3: 2008-2009 (\%) & $1464(75.9 \%)$ & $2670(70.12 \%)$ \\
Year 4: 2009-2010 (\%) & $1723(89.3 \%)$ & $2605(68.4 \%)$ \\
\hline
\end{tabular}

whereas in Tanzania they begin primary school at 7 years of age. Additional details are given below.

5.1. Absenteeism. Absenteeism rates were presented as the number of days a student was absent compared to the number of days in the academic year. The results in Table 2 show a significant difference between groups; both eversupported OVC (5.1\%) and non-OVC (5.5\%) had significantly lower absenteeism rates than never-supported OVC (6.4\%). However, we found marked differences in absenteeism rates between Tanzania and Uganda that we are unable to explain. In Uganda, consistent patterns emerged: eversupported OVC (3.6\%) showed much lower absenteeism rates than either their never-supported OVC $(6.8 \%)$ or nonOVC (6.1\%) counterparts. In Tanzania, ever-supported OVC students $(6.5 \%)$ had statistically higher absenteeism rates compared to never-supported OVC (5.7\%), but not when compared to non-OVC students (6.1\%).

Table 3 shows the breakdown of absenteeism by gender and type of student support. Female students had slightly lower absenteeism rates compared to male students throughout the different support groups in both countries although only one of these gender differences reached statistical significance that is for non-OVC in Uganda.

5.2. Dropout. Dropout rates in this study were significantly below the national averages (Tanzania 2.2\%, Uganda estimated at 14-15\%). Analyses are summarized in Table 4. The striking difference between the two countries is not easily explained. Anecdotal evidence suggested that, with the introduction of Universal Secondary Education (USE) in Uganda, there has been an increase in overall school enrollments (borne out in QUANT 2), but there are still significant fees, (our costing analysis identified that the out-of-pocket expenditures are $\$ 130$ per child, per year in Uganda), and many parents could not continue to pay for schooling. Conversely in Tanzania, where there is no USE, and students and parents know that they have to pay for their entire secondary education, out-of-pocket expenditures are lower (\$64 per child per year), and there is a better understanding of the costs before entering school.

In addition, there has been high-level political campaigning in the study districts in Tanzania in the last four years. This has included the building of multiple new secondary schools, and placing emphasis on the importance of attendance and the penalties for truancy and drop out.

Dropout rates for OVC in general were higher than for non-OVC, and never-supported OVC had a higher dropout rate than ever-supported OVC. Perhaps most importantly, both male and female never-supported OVC were almost twice as likely to drop out as other children.

5.3. National Examination Scores. Tanzania offers two nationally scored examinations for all students, at the end of Form II and at the end of Form IV. Uganda only offers one national examination at the end of Standard IV. Each country has a core curriculum which includes English, Math, Physics, and Chemistry, with electives possible in Civics and Kiswahili (Tanzania), and Geography and Biology (Uganda). In addition to the individual grades for each subject, the scores are aggregated to a single letter grade. Each country applies a different scoring system, so cross-country comparison is inappropriate.

5.3.1. Form II Exams (Tanzania). Mean examination scores on Form II exams are given in Table 5. With the exception of Math on which students obtained an average of $\mathrm{F}$, the majority of students obtain passing grades (C or D). Most notably ever-supported OVC consistently outscored their never-supported peers on every subject with the results being statistically significant for English, Math, Physics, and Chemistry. Table 6 presents the overall pass rates between the different types of NGO support and demonstrates the low success rates on Form II exams for all groups of students. It is noteworthy that never-supported OVC students were statistically less likely to pass this exam compared to their peers. As Form II exam pass rates are disaggregated by gender (Table 7), we see that across the different types of students, female students are much less likely to pass their Form II exams when compared to their male counterparts. This gender analysis is statistically significant for both non-OVC students and never supported OVC students.

5.3.2. Form IV Exams (Tanzania). Mean examination scores on Form IV exams in Tanzania are given in Table 8. Most students obtained a minimal passing grade of $\mathrm{D}$ in almost all their subjects. Non-OVC students had higher scores 
TABLE 2: Mean student absenteeism rate, stratified by country.

\begin{tabular}{lccc}
\hline $\begin{array}{l}\text { Mean student absenteeism rate } \\
\text { (2006-2009) }\end{array}$ & OVC ever supported & OVC never supported & Non-OVC \\
\hline Tanzania $(n=1783)$ & $6.5 \%{ }^{*}$ & $5.7 \%{ }^{*}$ & $6.8 \%{ }^{*}$ \\
Uganda $(n=2792)$ & $3.6 \%{ }^{*}$ & $6.4 \%^{*+}$ & $5.1 \%{ }^{*}$ \\
Total $(n=4575)$ & $5.1 \%^{*}$ & $5.6 \%$ & $5.5 \%{ }^{+}$ \\
\hline Africare UG-block grant $(n=721)$ & $3.2 \%{ }^{*}$ & $8.4 \%^{*+}$ & $6.1 \%{ }^{*}$ \\
ICOBI UG-block grant $(n=1010)$ & $3.7{ }^{*}$ & $6.1 \%{ }^{*}$ & $4.5 \%{ }^{+}$ \\
AVSI UG-scholarship $(n=1059)$ & $3.6 \%{ }^{*}$ & $5.8 \%$ & $5.0 \%{ }^{*}$ \\
Africare TZ-block grant $(n=1152)$ & $6.2 \%$ & $5.4 \%$ & $6.3 \%$ \\
CRS TZ-scholarship $(n=631)$ & $7.0 \%$ & $5.7 \%$ \\
\hline
\end{tabular}

Paired $t$-test compared the means of three sets of two groups: OVC ever supported versus OVC never supported; OVC never supported versus Non-OVC; OVC ever supported versus Non-OVC. Paired significance is noted accordingly.

* Student status significantly different at $P<0.05$.

${ }^{+}$Student status significantly different at $P<0.05$.

TABLE 3: Mean student absenteeism rate by student status, stratified by gender.

\begin{tabular}{lcc}
\hline & Male & Female \\
\hline $\begin{array}{l}\text { Mean student absenteeism rate } \\
\text { (Uganda and Tanzania) }\end{array}$ & \\
$\quad$ Non-OVC $(n=1809)$ & $5.7 \%$ & $5.3 \%$ \\
$\quad$ OVC never supported $(n=1871)$ & $5.3 \%$ & $4.9 \%$ \\
$\quad$ OVC ever supported $(n=895)$ & $6.3 \%$ & $5.9 \%$ \\
Mean student absenteeism rate (Uganda) & & \\
$\quad$ Non-OVC ( $n=1142)$ & $6.8 \%{ }^{*}$ & $6.0 \%{ }^{*}$ \\
$\quad$ OVC never supported ( $n=1198)$ & $7.4 \%$ & $6.2 \%$ \\
$\quad$ OVC ever supported $(n=452)$ & $5.8 \%$ & $5.5 \%$ \\
Mean student absenteeism rate (Tanzania) & & \\
$\quad$ Non-OVC ( $n=667)$ & $5.4 \%$ & $4.7 \%$ \\
$\quad$ OVC never supported ( $n=673)$ & $3.8 \%$ & $3.5 \%$ \\
OVC ever supported $(n=443)$ & $7.1 \%$ & $6.0 \%$ \\
\hline
\end{tabular}

Paired $t$-test compared the means of two groups of observations: male versus female students.

${ }^{*}$ Gender significantly different at $P<0.05$.

compared to OVC students, with statistically significant differences in English, Civics, and Kiswahili. Table 9 shows the small percentage of students that passed the Form IV national exams in Tanzania. No statistical significance was obtained between the different types of support due to the small number of students that actually took this exam in this sample. As Form IV exam pass rates are disaggregated by gender in Tanzania (Table 10), we see that, across the different types of students, female students were less likely to pass their Form IV exams when compared to their male counterparts.

5.3.3. Standard IV Exams (Uganda). As shown in Table 11, there were no significant differences among the types of student support groups on any of the subject areas that were measured on Uganda's Standard IV National Examinations. All groups scored relatively better on the examinations of English and Geography and scored poorly, with barely passing scores, in the other subject areas. When differentiated by type of NGO support, Table 12 reveals that Ugandan students in schools supported by block grants through ICOBI showed one significant difference. Here the proportion of students passing their Standard IV National Exams was significantly lower for never-supported OVC students $(36.3 \%)$ than for non-OVC students (60.3\%) and for ever-supported OVC students (64.4\%). The difference between the latter two groups was not significant. Table 13 shows that gender comparisons of pass rates on the Ugandan Standard IV National Exam were consistent across all three types of student status. Males performed significantly better than females whether the comparisons were between non-OVC, never-supported OVC, or ever-supported OVC.

5.4. Evidence from Qualitative Data. As described earlier, this study focused on QUANT I data from a large and comprehensive study of assistance to OVC. Qualitative data gained from focus groups with small groups of students of the same gender will be reported elsewhere. However, especially in light of the relatively superior academic performance of OVCs in Tanzania on Form II examinations, it was of special interest to note how OVCs compared their own academic performance to that of their non-OVC counterparts. Fully 22 out of 26 respondents in Tanzania thought they either performed equally or studied harder than non-OVCs. A female OVC replied "I can say the performance is balanced because we are getting the same marks with those regular students." A male observed "There is a difference....So many non-OVCs do not bother studying hard because they know they have parents to depend on." Another Tanzanian female explained "Academic performance for OVCs can be good because they always think about the school, whereas regular students can be fooled by the richness of their parents." This perception appeared to be widely held and borne out by the findings.

\section{Significance of the Study}

This study was ground breaking for its provision of reliable data to address previously unanswered questions about the impact of various forms of investment in secondary schooling for orphans and vulnerable children of both genders. 
TABLE 4: Drop out rate by student status and by gender, 2006-2010.

\begin{tabular}{|c|c|c|}
\hline & $\begin{array}{c}\text { Proportion } \\
(\%)\end{array}$ & $\begin{array}{c}\text { Odds ratio } \\
(95 \% \mathrm{CI})\end{array}$ \\
\hline \multicolumn{3}{|l|}{ Country } \\
\hline \multicolumn{3}{|l|}{ Tanzania } \\
\hline Non-OVC (ref.) & $4 / 710(0.6 \%)$ & 1.00 \\
\hline OVC never supported & $7 / 720(1.0 \%)$ & $1.73(0.51-5.95)$ \\
\hline OVC ever supported & $12 / 496(2.4 \%)$ & $4.38(1.40-13.65)^{*}$ \\
\hline \multicolumn{3}{|l|}{ Uganda } \\
\hline Non-OVC (ref.) & $126 / 1474(8.6 \%)$ & 1.00 \\
\hline OVC never supported & $222 / 1511(14.7 \%)$ & $3.20(2.57-3.98)^{*}$ \\
\hline OVC ever supported & $85 / 768(11.1 \%)$ & $1.33(1.00-1.78)$ \\
\hline \multicolumn{3}{|l|}{ Total } \\
\hline Non-OVC (ref.) & $130 / 2184(6.0 \%)$ & 1.00 \\
\hline OVC never supported & $229 / 2231(10.3 \%)$ & $1.81(1.44-2.26)^{*}$ \\
\hline OVC ever supported & 97/1264 (7.7\%) & $1.31(1.00-1.72)$ \\
\hline \multicolumn{3}{|l|}{ Gender } \\
\hline \multicolumn{3}{|l|}{ Male } \\
\hline Non-OVC (ref.) & 71/1194 (6.0\%) & 1.00 \\
\hline OVC never supported & $116 / 1174(9.9 \%)$ & $1.73(1.28-2.36)^{*}$ \\
\hline OVC ever supported & $44 / 615(7.2 \%)$ & $1.22(0.83-1.80)$ \\
\hline \multicolumn{3}{|l|}{ Female } \\
\hline Non-OVC (ref.) & $59 / 990(6.0 \%)$ & 1.00 \\
\hline OVC never supported & $113 / 1057(10.7 \%)$ & $1.89(1.36-2.62)^{*}$ \\
\hline OVC ever supported & $53 / 649(8.2 \%)$ & $1.40(0.95-2.06)$ \\
\hline \multicolumn{3}{|l|}{ NGO support } \\
\hline \multicolumn{3}{|l|}{ Africare UG-block grant } \\
\hline Non-OVC (ref.) & $48 / 491(9.8 \%)$ & 1.00 \\
\hline OVC never supported & $88 / 493(17.9 \%)$ & $2.01(1.38-2.92)^{*}$ \\
\hline OVC ever supported & $39 / 247(15.8 \%)$ & $1.73(1.10-2.72)^{*}$ \\
\hline \multicolumn{3}{|l|}{ ICOBI UG-block grant } \\
\hline Non-OVC (ref.) & $43 / 475(9.1 \%)$ & 1.00 \\
\hline OVC never supported & $98 / 517(19.0 \%)$ & $2.35(1.60-3.45)^{*}$ \\
\hline OVC ever supported & $31 / 255(12.2 \%)$ & $1.39(0.85-2.27)$ \\
\hline \multicolumn{3}{|l|}{ AVSI UG-scholarship } \\
\hline Non-OVC (ref.) & $35 / 508(6.9 \%)$ & 1.00 \\
\hline OVC never supported & $36 / 501(7.2 \%)$ & $1.05(0.65-1.70)$ \\
\hline OVC ever supported & $14 / 264(5.3 \%)$ & $0.76(0.40-1.43)$ \\
\hline \multicolumn{3}{|l|}{ Africare TZ-block grant } \\
\hline Non-OVC (ref.) & $3 / 466(0.6 \%)$ & 1.00 \\
\hline OVC never supported & $4 / 469(0.9 \%)$ & $1.33(0.30-5.96)$ \\
\hline OVC ever supported & $7 / 242(2.9 \%)$ & $4.60(1.18-17.94)^{*}$ \\
\hline \multicolumn{3}{|l|}{ CRS TZ-scholarship } \\
\hline Non-OVC (ref.) & $1 / 244(0.4 \%)$ & 1.00 \\
\hline OVC never supported & $3 / 250(1.2 \%)$ & $2.95(0.30-28.57)$ \\
\hline OVC ever supported & $5 / 524(2.0 \%)$ & $2.34(0.27-20.15)$ \\
\hline
\end{tabular}

${ }^{*}$ Student status significantly different at $P<0.05$.

6.1. Education Delivery Models. Each of the five NGOs supporting OVC to attend secondary school that we studied was successful in allowing limited numbers of OVC who would not have been able to receive secondary education, to go to school. From that perspective, every organization attained its programmatic goals. However, there are limitations presented by each education delivery mode.
6.1.1. Block Grants. Two (Africare UG and ICOBI UG) of the three block grant programs showed significant improvements in school attendance of supported OVC over their nonOVC and nonsupported OVC counterparts. Furthermore, the same programs saw significantly increased drop-out rates among nonsupported OVC when compared to non-OVC. Finally, supported OVC in Tanzania (Africare TZ) performed better on their aggregate scores for Form II, but the result was not statistically significant. There were no measurable differences on aggregate scores for Form IV, and individual subject scores showed that OVC performed at the same level as non-OVC.

6.1.2. Scholarship. One (AVSI UG) of two scholarship programs demonstrated significant improvements in school attendance of supported OVC over their non-OVC and supported OVC counterparts. In addition, there were no observed differences in either scholarship approach between supported OVC and their non-OVC counterparts. Finally, there were no differences on Form II or Form IV aggregate scores as the numbers were too small to look at individual subjects.

\subsection{Gender Issues}

6.2.1. Absenteeism. There is a great deal of discussion in both the popular and scientific literature about the effect of menstruation on girls' ability to maintain attendance and perform adequately in school. The argument is that the lack of sanitary napkins prevents girls from attending school during menstruation, and that even when sanitary napkins are available, lack of privacy and adequate sanitation make it difficult for girls to change napkins. Some authors have argued that this may result in between 18-36 days of school lost in a 180 day school year (Mooijman et al. [11]). Our results are therefore surprising in that for every group-supported OVC, non-supported OVC, and non-OVC girls have lower rates of absenteeism than boys. If menstruation was a significant cause of absenteeism, we would have expected to see the opposite. Our findings concur with the recent publication by Oster and Thornton [12] who concluded that actual lost time at school due to menses was minimal (half a day a year in Nepal). This is not to suggest that aids to good hygiene and privacy are not important human rights for all young women, simply that our observations would not support that menstruation is a significant contributor to absenteeism.

6.2.2. Dropout. There was no difference in the dropout rates between boys and girls by student status in any of the schools in our study. Moreover, OVC who were supported did not have a significantly higher rate of dropout than nonOVC; however, never-supported OVC of both genders had significantly higher drop-out rates. We conclude therefore that the support provided to OVC was protective against dropping out for both boys and girls.

6.2.3. Academic Performance. Results indicated that female students in both Tanzania and Uganda were much less likely 
TABLE 5: Tanzanian form II national examination scores, 2006-2010.

\begin{tabular}{lccr}
\hline & OVC ever supported & OVC never supported & Non-OVC \\
\hline Mean exam scores $(\mathrm{SD})^{*}$ & & & \\
English $(n=1339)$ & $30.5(17.91)^{*+}$ & $25.9(12.9)^{*}$ & $27.5(15.1)^{+}$ \\
Civics $(n=1340)$ & $33.5(14.5)^{*}$ & $31.5(12.9)$ & $31.1(13.5)^{*}$ \\
Geography $(n=613)$ & $47.1(15.5)$ & $16.2(16.7)$ & $46.1(14.7)$ \\
Math $(n=1340)$ & $19.2(18.2)^{*+}$ & $33.0(15.7)^{*}$ & $15.5(14.7)^{+}$ \\
Physics $(n=1274)$ & $36.6(15.5)^{*}$ & $32.1(15.1)^{*}$ & $34.3(15.5)$ \\
Chemistry $(n=1293)$ & $36.1(13.9)^{*}$ & $36.8(15.4)$ & $33.6(14.5)$ \\
Biology $(n=613)$ & $37.6(14.3)$ & $47.9(17.7)$ & $36.9(12.3)$ \\
Kiswahili $(n=1340)$ & $45.8(18.4)$ & $46.6(18.5)$ \\
\hline
\end{tabular}

Paired $t$-test compared the means of three sets of two groups: OVC ever supported versus OVC never supported; OVC never supported versus non-OVC; OVC ever supported versus Non-OVC. Paired significance is noted accordingly.

${ }^{*}$ Student status significantly different at $P<0.05$ between designated groups.

${ }^{+}$Student status significantly different at $P<0.05$ between designated groups.

${ }^{\ddagger}$ Exam scores are out of 100 points: $100-81=A, 80-61=B, 60-41=C, 40-21=D, 20-0=F$.

(Higher points indicate better exam performance.)

TABLE 6: Tanzanian form II national exam pass rate by student status, 2006-2010.

\begin{tabular}{ccc}
\hline & $\begin{array}{c}\text { Proportion } \\
(\%)\end{array}$ & $\begin{array}{c}\text { Odds ratio } \\
(95 \% \mathrm{CI})\end{array}$ \\
\hline NGO support & & \\
Africare TZ-block grant & & 1.00 \\
Non-OVC (ref.) & $83 / 400(20.8 \%)$ & 0.65 \\
OVC never supported & $57 / 390(14.6 \%)$ & $(0.45-0.95)^{*}$ \\
OVC ever supported & $27 / 154(17.5 \%)$ & $0.81(0.50-1.31)$ \\
CRS TZ-scholarship & & \\
Non-OVC (ref.) & $35 / 111(31.5 \%)$ & 1.00 \\
OVC never supported & $28 / 107(26.2 \%)$ & $0.77(0.43-1.39)$ \\
OVC ever supported & $24 / 73(32.9 \%)$ & $1.06(0.55-2.00)$ \\
\hline
\end{tabular}

${ }^{*}$ Student status significantly different at $P<0.05$.

TABLE 7: Tanzanian form II national exam pass rate by gender, 2006-2010.

\begin{tabular}{lcc}
\hline & Proportion (\%) & Odds ratio (95\% CI) \\
\hline Student status & & \\
Non-OVC & & \\
$\quad$ Male (ref.) & $76 / 275(27.6 \%)$ & 1.00 \\
Female & $42 / 234(18.0 \%)$ & $0.57(0.37-0.88)^{*}$ \\
OVC never supported & & \\
Male (ref.) & $58 / 287(20.2 \%)$ & 1.00 \\
Female & $27 / 206(13.1 \%)$ & $0.60(0.36-0.98)^{*}$ \\
OVC ever supported & & \\
Male (ref.) & $31 / 113(27.4 \%)$ & 1.00 \\
Female & $20 / 114(17.5 \%)$ & $0.56(0.30-1.06)$ \\
\hline
\end{tabular}

${ }^{*}$ Student status significantly different at $P<0.05$.

to pass their National Form II and Form IV or Standard IV Examinations compared to their male counterparts. The same pattern holds true across all the different support groups. Females perform well or better than males on other measures of academic success (they show lower absenteeism and lower dropout rates), but they perform consistently lower than males on academic tests.

\section{Limitations}

7.1. Lack of Knowledge of the Households from Which the Supported OVCCame. Many contextual factors which would help to explain issues raised in this study cannot be answered because funding was not sufficient to conduct a household survey of supported OVC to understand their social, economic, parental, living, and other conditions. This lack of information does not affect the relevance or quality of the data collected at schools or in focus groups, but it does limit the ability to interpret some of the findings around absenteeism and dropout. It also limits the ability to provide direct comparisons between schools as the details of the populations served are not well known.

7.2. Children "Aging out" of the Program. Because of early statements about who constituted an OVC by the President's Emergency Plan for AIDS Relief (PEPFAR), decisions were made early on by the various programs that educational support would not be continued beyond the age of 18 years (in the last year of project implementation this was reversed but did not affect the cohort of students being studied). The consequence of this is that children who initiated the program found themselves losing their educational support in Form IV (and sometimes earlier). In Tanzania this resulted in the majority of Form IV students being lost to followup, and this in turn affected the results for the final year of the cohort particularly for Form IV examinations.

7.3. Lack of Concentrated Populations of Supported OVC. The finding that both of the scholarship programs (CRS and AVSI) did not have populations of 50 or more supported OVC in any individual secondary school only became clear as individual recipient lists were examined. This required that 
TABLE 8: Form IV national examination scores, Tanzania.

\begin{tabular}{lccc}
\hline & OVC ever supported & OVC never supported & Non-OVC \\
\hline Mean exam scores $(\mathrm{SD})^{\ddagger}$ & & & $4.5(0.7)^{*}$ \\
English $(n=152)$ & $4.2(0.7)$ & $4.5(0.7)^{*}$ & $4.1(0.7)^{*}$ \\
Civics $(n=152)$ & $4.3(0.8)^{+}$ & $4.9(0.4)$ & $3.9(0.8)^{*+}$ \\
Math $(n=152)$ & $4.5(0.9)$ & $3.8(0.8)$ & $4.8(0.6)$ \\
Physics $(n=45)$ & $4.2(0.7)$ & $3.8(0.8)$ & $4.2(0.8)$ \\
Chemistry $(n=45)$ & $4.3(0.7)$ & $4.5(0.7)^{*}$ & $4.1(0.9)$ \\
Kiswahili $(n=151)$ & $4.4(0.8)^{+}$ & $3.9(0.7)^{*+}$ \\
\hline
\end{tabular}

Paired $t$-test compared the means of three sets of two groups: OVC ever supported versus OVC never supported; OVC never supported versus non-OVC; OVC ever supported versus non-OVC. Paired significance is noted accordingly.

* Student status significantly different at $P<0.05$ between designated groups.

${ }^{+}$Student status significantly different at $P<0.05$ between designated groups.

${ }^{\ddagger}$ Exam scores are out of 5 points: $1=A, 2=B, 3=C, 4=D, 5=F$.

(Lower points indicate better exam performance.)

TABle 9: Tanzanian form IV national exam pass rate by student status, 2006-2010.

\begin{tabular}{ccc}
\hline & Proportion (\%) & Odds ratio (95\% CI) \\
\hline $\begin{array}{c}\text { NGO support } \\
\text { Africare TZ-block grant }\end{array}$ & \\
Non-OVC (ref.) & $12 / 60(20.0 \%)$ & 1.00 \\
OVC never supported & $2 / 19(10.5 \%)$ & $0.47(0.10-2.32)$ \\
OVC ever supported & $2 / 32(6.3 \%)$ & $0.27(0.06-1.28)$ \\
CRS TZ-scholarship & & \\
Non-OVC (ref.) & $0 / 1(0 \%)$ & 1.00 \\
OVC never supported & $0 / 1(0 \%)$ & - \\
OVC ever supported & $0 / 4(0 \%)$ & - \\
\hline
\end{tabular}

* Student status significantly different at $P<0.05$.

TABle 10: Tanzanian Form IV national exam pass rate by student status, by gender, 2006-2010.

\begin{tabular}{lcc}
\hline & Proportion (\%) & Odds ratio (95\% CI) \\
\hline $\begin{array}{l}\text { Student status } \\
\text { Non-OVC }\end{array}$ & \\
$\quad$ Male (ref.) & $9 / 37(24.3 \%)$ & 1.00 \\
$\quad$ Female & $3 / 24(12.5 \%)$ & $0.44(0.10-1.85)$ \\
OVC never supported & & 1.00 \\
$\quad$ Male (ref.) & $1 / 9(11.1 \%)$ & $0.80(0.04-14.89)$ \\
$\quad$ Female & $1 / 11(9.1 \%)$ & 1.00 \\
OVC ever supported & & \\
$\quad$ Male (ref.) & $1 / 14(7.1 \%)$ & $0.62(0.04-10.78)$ \\
$\quad$ Female & $1 / 22(4.6 \%)$ & \\
\hline
\end{tabular}

${ }^{*}$ Student status significantly different at $P<0.05$.

a much larger sample size of schools be made for both NGOs. In turn, directly matched control schools could not be chosen for all schools in the CRS and AVSI samples. At CRS, schools there were often only five or six study students, and therefore the control students were picked from the same schools.

7.4. Differences in the Educational Systems between Uganda and Tanzania. Children start school one year younger in
Uganda than in Tanzania, with the result that the OVC in our sample in Tanzania were all one year older than their equivalent grade in Uganda. Fortunately, while a year's age difference is significant in younger age groups, it has little bearing on the ability to perform academically after midadolescence, and we do not anticipate that age would result in any differences in pass rates between the two countries. However, the later start date in Tanzania meant that many students in Form IV were over 18 and therefore no longer eligible for OVC support. This is reflected in the very low numbers of exam results for students in Form IV in Tanzania which in turn limited our ability to draw significant conclusions on Form IV academic performance in this environment.

In 2007, Uganda introduced Universal Secondary Education, eliminating tuition fees for public secondary school. In contrast, fees for secondary education are still charged in Tanzanian public schools. The fees in Tanzania are 20,000 TZS per term, which is then matched by the government. However, secondary education in Uganda is not free, and fees in Tanzania are not limited to the official government fees. The reality is that, in both countries, the cost of actually attending secondary school is approximately the same (in excess of 100,000 Shillings). The actual fees charged are not standardized and may differ from school to school, and even from year to year in the same school. We therefore do not believe that USE in Uganda presents a problem in making country-to-country comparisons.

\section{Conclusion}

PEPFAR programming for OVC prioritizes support for primary school education and recommends considering the "feasibility" of supporting postprimary school education, especially the transition for girls [13]. This study is the first study to demonstrate that providing support to OVC to attend secondary school is not only important, but effective. We demonstrate that supported children performed at least as well as their non-OVC peers and in some cases better. Both block grants and scholarships can increase access to secondary education for OVC who do not have the financial 
TABLE 11: Standard IV national examination scores, Uganda.

\begin{tabular}{lllr}
\hline & OVC ever-supported & OVC never supported & non-OVC \\
\hline Mean exam scores $(\mathrm{SD})^{\ddagger}$ & & & \\
English $(n=738)$ & $6.2(1.7)$ & $6.0(1.9)$ & $6.9(1.8)$ \\
Geography $(n=356)$ & $6.1(1.5)$ & $7.2(1.8)$ & $7.9(1.6)$ \\
Math $(n=738)$ & $7.2(1.5)$ & $8.0(1.7)$ & $7.1(1.7)$ \\
Physics $(n=738)$ & $8.3(1.2)$ & $8.2(1.6)$ & $8.0(1.5)$ \\
Chemistry $(n=736)$ & $8.4(1.1)$ & $7.4(1.8)$ & $8.2(1.3)$ \\
Biology $(n=355)$ & $7.6(1.4)$ & & $7.4(1.5)$ \\
\hline
\end{tabular}

* Significantly different at $P<0.05$.

${ }^{\ddagger}$ Exam scores are out of 9 points: $1=D 1,2=D 2,3=C 3,4=C 4,5=C 5,6=C 6,7=P 7,8=P 8,9=F$.

(Lower points indicate better exam performance.)

TABLE 12: Ugandan standard IV national exam pass rates across NGOs by student status, 2006-2010.

\begin{tabular}{|c|c|c|}
\hline & Proportion (\%) & Odds ratio $(95 \% \mathrm{CI})$ \\
\hline \multicolumn{3}{|l|}{ NGO support } \\
\hline \multicolumn{3}{|l|}{ Africare UG-block grant } \\
\hline Non-oVC (ref.) & $182 / 285(63.9 \%)$ & 1.00 \\
\hline OVC never supported & $87 / 145(60.0 \%)$ & $0.56(0.56-1.28)$ \\
\hline OVC ever supported & $133 / 213(62.4 \%)$ & $0.94(0.65-1.36)$ \\
\hline \multicolumn{3}{|c|}{ ICOBI UG-block grant } \\
\hline Non-OVC (ref.) & $94 / 156(60.3 \%)$ & 1.00 \\
\hline OVC never supported & $49 / 135(36.3 \%)$ & $0.38(0.23-0.60)^{*}$ \\
\hline OVC ever supported & $38 / 59(64.4 \%)$ & $1.19(0.64-2.22)$ \\
\hline \multicolumn{3}{|l|}{ AVSI UG scholarship } \\
\hline Non-OVC (ref.) & $185 / 269(68.8 \%)$ & 1.00 \\
\hline OVC never supported & $\mathrm{d} 184 / 261(70.5 \%)$ & $1.09(0.75-1.57)$ \\
\hline OVC ever supported & $88 / 113(77.9 \%)$ & $1.60(0.96-2.67)$ \\
\hline
\end{tabular}

${ }^{*}$ Student status significantly different at $P<0.05$.

TABLE 13: Ugandan standard IV national exam pass rates by gender, 2006-2010.

\begin{tabular}{lcc}
\hline & Proportion (\%) & Odds ratio (95\% CI) \\
\hline $\begin{array}{l}\text { Student status } \\
\text { Non-OVC }\end{array}$ & \\
$\quad$ Male (ref.) & $289 / 421(68.6 \%)$ & 1.00 \\
$\quad$ Female & $172 / 289(59.5 \%)$ & $0.67(0.49-0.92)^{*}$ \\
OVC never supported & & \\
$\quad$ Male (ref.) & $193 / 295(65.4 \%)$ & 1.00 \\
$\quad$ Female & $126 / 245(51.4 \%)$ & $0.56(0.40-0.79)^{*}$ \\
OVC ever supported & & \\
Male (ref.) & $154 / 198(77.8 \%)$ & 1.00 \\
Female & $105 / 188(55.9 \%)$ & $0.36(0.23-0.56)^{*}$ \\
\hline
\end{tabular}

${ }^{*}$ Student status significantly different at $P<0.05$.

means to attend school. This supports the findings of a recent study of OVC programs suggesting that the most significant factor in improving attendance at school (especially for girls) is payment of school fees rather than the provision of stationary, books, and uniforms [14]. There are also other societal factors that affect the educational outcomes beyond paying school fees, such as nutritional status, psychological wellbeing, and physical safety. These need to be addressed systematically as school support is provided.

Large sums of money have been invested to support children to attend schools; for example, education support accounts for almost $50 \%$ of the $\$ 1.6$ billion invested in OVC by PEPFAR. However, monitoring data has focused on student enrollment. The paucity of data on student outcomes and other measures of school quality has limited severely what researchers can say to inform decision making about educational policy and attainment in developing countries. It was extremely difficult for the researchers to access data on student achievement. Workshops presenting the findings to local and national leaders underscored the lack of information for informed decision making. A thorough search of the literature confirms this frustration. There is an urgent need for research that examines educational outcomes of investments in primary school education, and how to effectively steer children through the transition from primary school to secondary school.

Research partners from Makerere University in Uganda and the Center for Strategic Research and Development in Tanzania were instrumental in identifying and training local researchers to participate in the challenging and rigorous data collection needed to obtain reliable information. This study could not have been down without their collaboration and particularly their leadership in training and overseeing the data collection in the field.

\section{Acknowledgments}

This study was funded by the US Agency for International Development (USAID) under contract no. GHH-I-00-0700023-00, beginning August 1, 2008. The content of this paper does not necessarily reflect the views, analysis, or policies of USAID.

\section{References}

[1] S. M. Lynch, "Cohort and life-course patterns in the relationship between education and health: a hierarchical approach," Demography, vol. 40, no. 2, pp. 309-331, 2003.

[2] S. Y. Chou, J. T. Liu, M. Grossman, and T. J. Joyce, "Parental education and child health: evidence from a natural experiment 
in Taiwan," American Economic Journal: Applied Economics, vol. 2, no. 1, pp. 33-61, 2010.

[3] E. Gakidou, K. Cowling, R. Lozano, and C. J. Murray, "Increased educational attainment and its effect on child mortality in 175 countries between 1970 and 2009: a systematic analysis," The Lancet, vol. 376, no. 9745, pp. 959-974, 2010.

[4] R. Monasch and J. T. Boerma, "Orphanhood and childcare patterns in sub-Saharan Africa: an analysis of national surveys from 40 countries," AIDS, vol. 18, no. 2, pp. S55-S65, 2004.

[5] A. Case, C. Paxson, and J. Ableidinger, "Orphans in Africa: parental death, poverty, and school enrollment," Demography, vol. 41, no. 3, pp. 483-508, 2004.

[6] C. Nyamukapa and S. Gregson, "Extended family's and women's roles in safeguarding orphans' education in AIDS-afflicted rural Zimbabwe," Social Science \& Medicine, vol. 60, no. 10, pp. 2155-2167, 2005.

[7] C. M. Miller, S. Gruskin, S. V. Subramanian, D. Rajaraman, and S. J. Heymann, "Orphan care in Botswana's working households: growing responsibilities in the absence of adequate support," American Journal of Public Health, vol. 96, no. 8, pp. 1429-1435, 2006.

[8] A. Case and C. Ardington, "The impact of parental death on school outcomes: longitudinal evidence from South Africa," Demography, vol. 43, no. 3, pp. 401-420, 2006.

[9] G. Bicego, S. Rutstein, and K. Johnson, "Dimensions of the emerging orphan crisis in sub-Saharan Africa," Social Science \& Medicine, vol. 56, no. 6, pp. 1235-1247, 2003.

[10] UNESCO, Fact Sheet: How Many Children in Africa Reach Secondary Education? UNESCO, Paris, France, 2006.

[11] A. Mooijman, M. Snel, S. Ganguly, and K. Shordt, Strengthening Water, Sanitation and Hygiene in Schools. A WASH Guidance Manual with a Focus on South Asia, IRC International Water and Sanitation Centre, The Hague, The Netherlands, 2005.

[12] E. Oster and R. Thornton, "Menstruation, sanitary products, and school attendance: evidence from a randomized evaluation," American Economic Journal: Applied Economics, vol. 3, no. 1, pp. 91-100, 2011.

[13] PEPFAR, "Guidance for Orphans and Vulnerable Children," Washington, DC, USA, 2012, http://www.pepfar.gov/documents/organization/195702.pdf.

[14] M. Bryant, J. Beard, L. Sabin et al., "PEPFAR's support for orphans and vulnerable children: some beneficial effects, but too little data, and programs spread thin," Health Affairs, vol. 31, no. 7, pp. 1508-1518, 2012. 


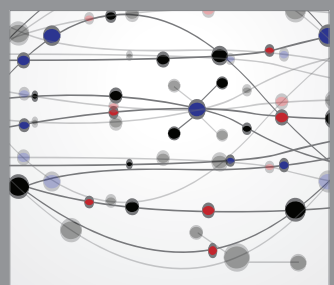

The Scientific World Journal
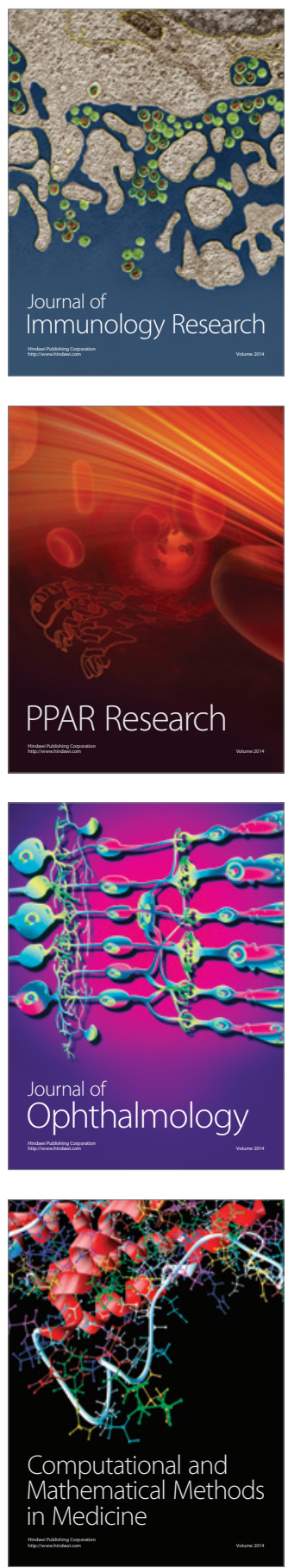

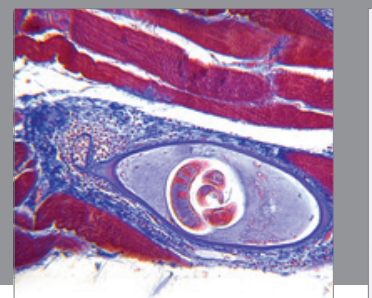

Gastroenterology

Research and Practice
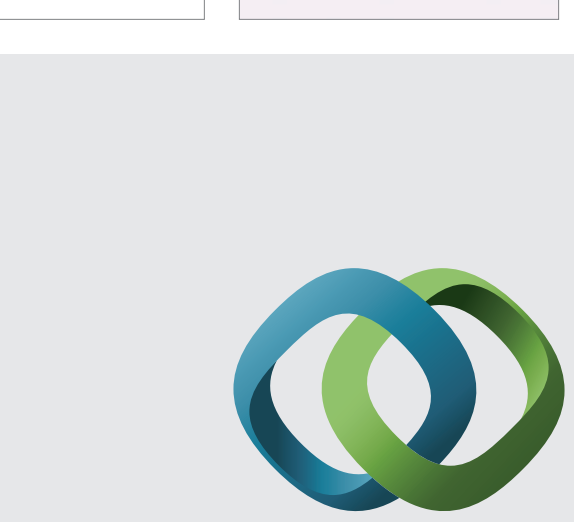

\section{Hindawi}

Submit your manuscripts at

http://www.hindawi.com
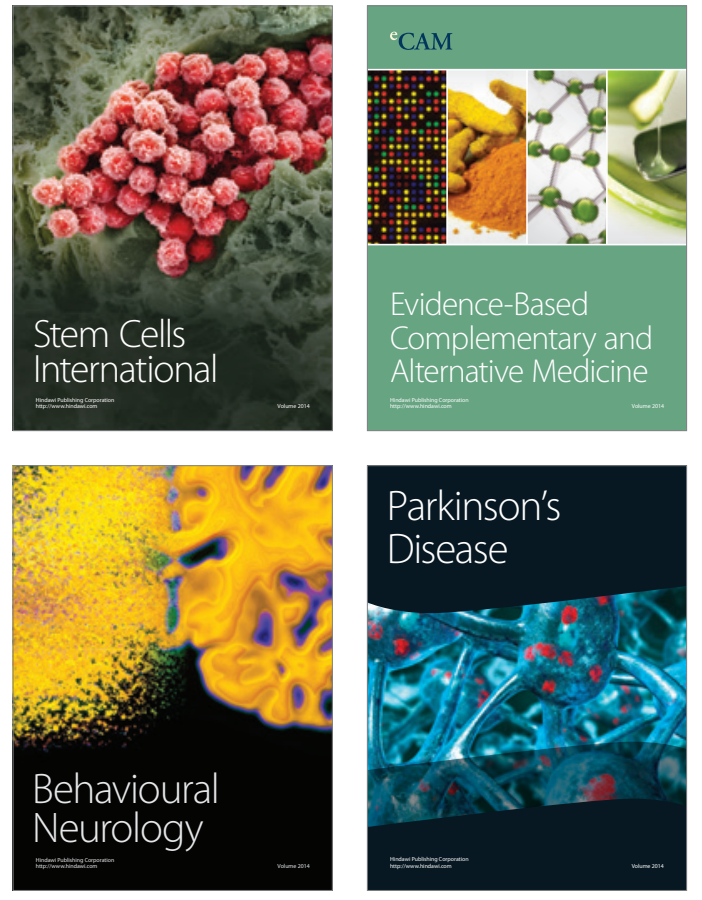
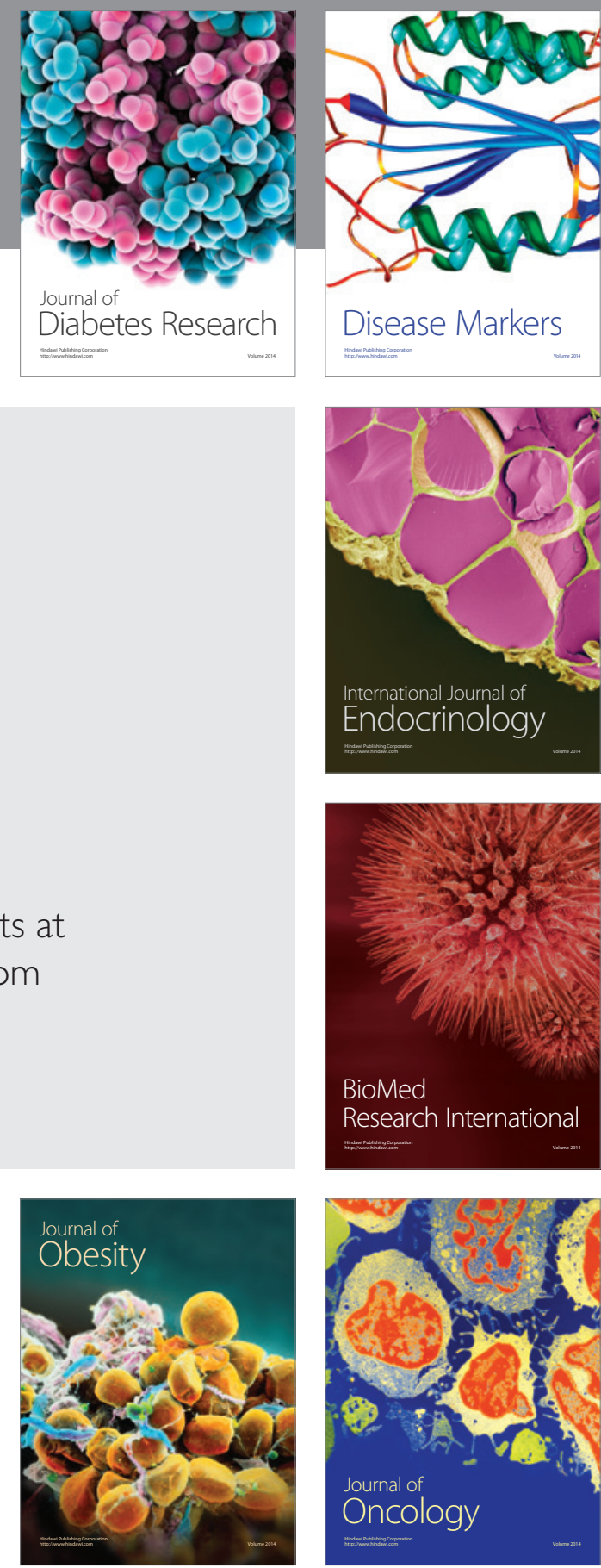

Disease Markers
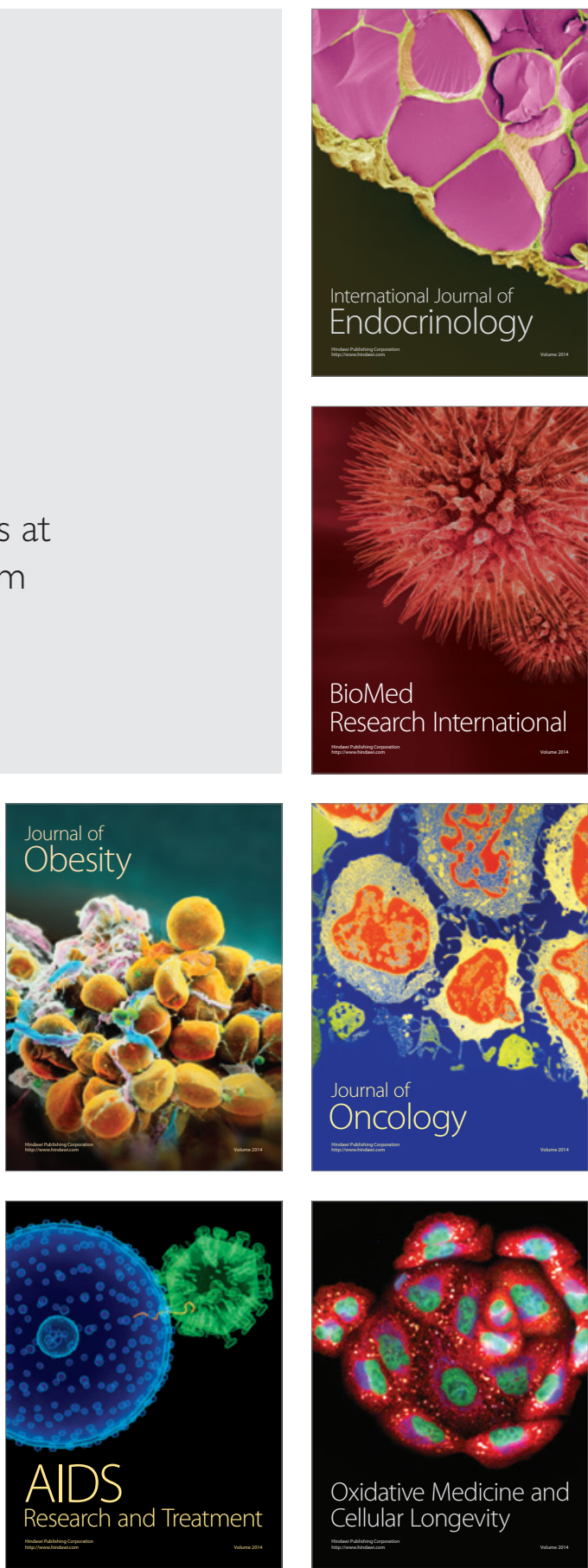